В. В. Борисов ${ }^{1}$, ст.викладач

\title{
МЕТОДЫ АВТОМАТИЗИРОВАННОГО СИНТЕЗА КОНЕЧНО- ЭЛЕМЕНТНЫХ МОДЕЛЕЙ СТЫКОВЫХ ЭЛЕМЕНТОВ В ПЛАНЕРЕ САМОЛЕТА
}

En The methods of the synthesis of structures of finite element models of power elements, which join the central section of the wing with the central section of fuselage of high wing scheme aircraft, are described. The features of definition of array of the node coordinates and the method of conversion of their numbers at the synthesis of local finite element model are described. Also described the sequence of the data exchange between the base models. Keywords: finite-element model, decomposition, synthesis of the finite element model, the reinforcing elements.

Ua Описуються методи синтезу структур скінченно-елементних моделей силових елементів, які з'єднують центроплан із центральним відсіком фюзеляжу літака схеми "високоплан". Описуються особливості визначення масиву координат вузлів та метод перерахунку їх номерів при створенні локальної моделі. Також описані послідовності обміну даними із базовими моделями.

\section{Введение}

Одной из важнейших задач, решаемых в процессе проектирования самолетов транспортной категории, является задача анализа распределения напряжений в стыковых элементах планера транспортного самолета, соединяющих центроплан с центральным отсеком фюзеляжа.

Главной проблемой, которую необходимо решать в процессе проектирования зоны стыка центроплана с фюзеляжем, является определение нагрузок, действующих на силовые элементы планера, расположенные в этой зоне. В отличие от стыка отъемной части кессона крыла (ОЧК) с центропланом, зона стыка центроплана с фюзеляжем включает несколько силовых элементов (рис. 1): вертикальные балки, передающие вертикальные нагрузки, продольные стенки, передающие тягу двигателей и сопротивление крыла.

Для размещения центроплана самолета, построенного по схеме "высокоплан", конструкция верхней части центрального отсека фюзеляжа должна содержать специальный вырез, который нарушает процесс передачи продольных усилий, возникающих при изгибе фюзеляжа. Эта проблема решается путем включения в конструкцию центрального отсека фюзеляжа

\footnotetext{
${ }^{1}$ Национальный технический университет Украини "Киевский политехнический институт", кафедра приборов и систем управления летательными аппаратами
} 
специальных соединительных дуг (рис. 1), передающих нагрузки с продольных силовых элементов фюзеляжа на нервюры центроплана.

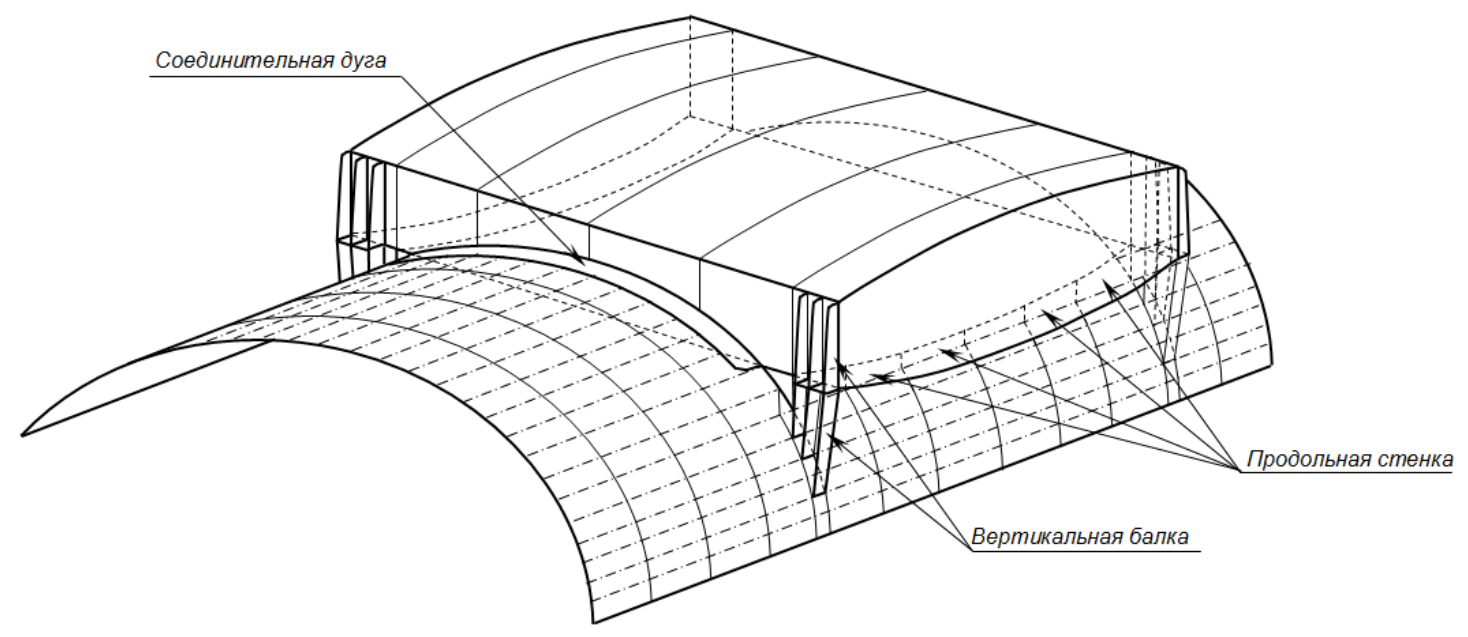

Рис. 1. Структура зоны стыка центроплана с фюзеляжем

Для восприятия продольных нагрузок в конструкцию нервюр включаются специальные "пояса" (рис. 2), которые соединяют переднюю и заднюю соединительные дуги.

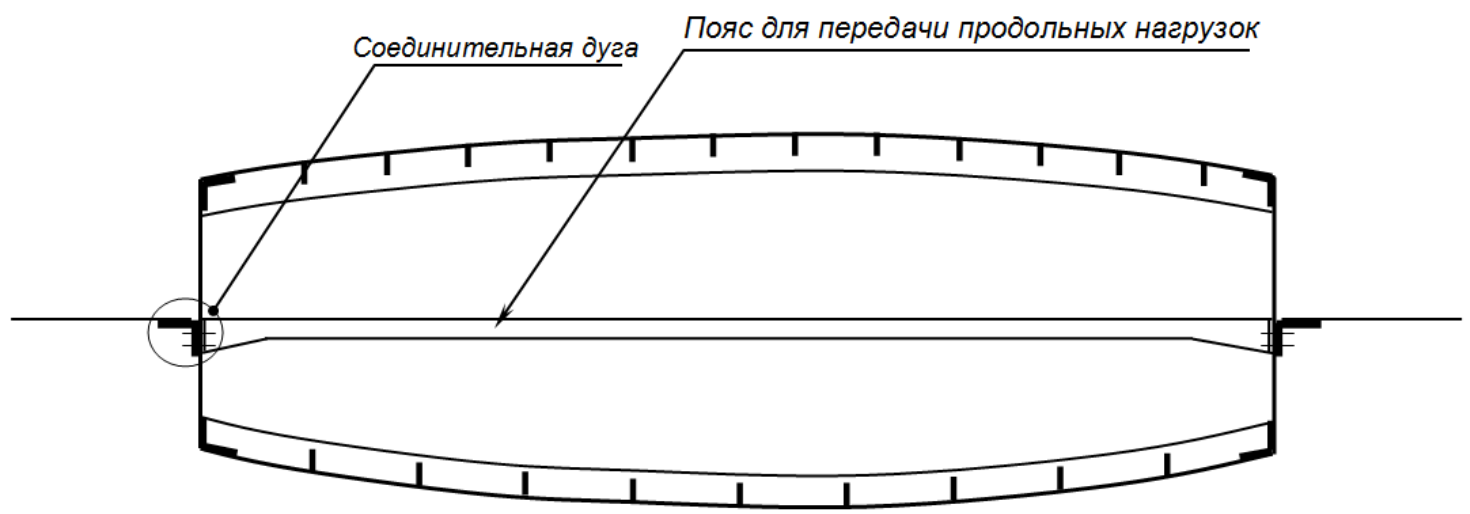

Рис. 2. Особенности структуры нервюры центроплана

Для соединения с указанными стыковыми элементами, конструкции фюзеляжа и центроплана содержат специальные силовые элементы: силовые шпангоуты (рис. 3), воспринимающие вертикальные усилия, и усиленные стрингеры, воспринимающие продольные нагрузки.

Существующие интегральные методы проектирования силовых элементов, соединяющих центроплан с центральным отсеком фюзеляжа, описанные в [1-3], не позволяют точно определять нагрузки, действующие на силовые элементы конструкции планера, поскольку интегральные методы расчета не позволяют учитывать взаимное влияние деформаций. 


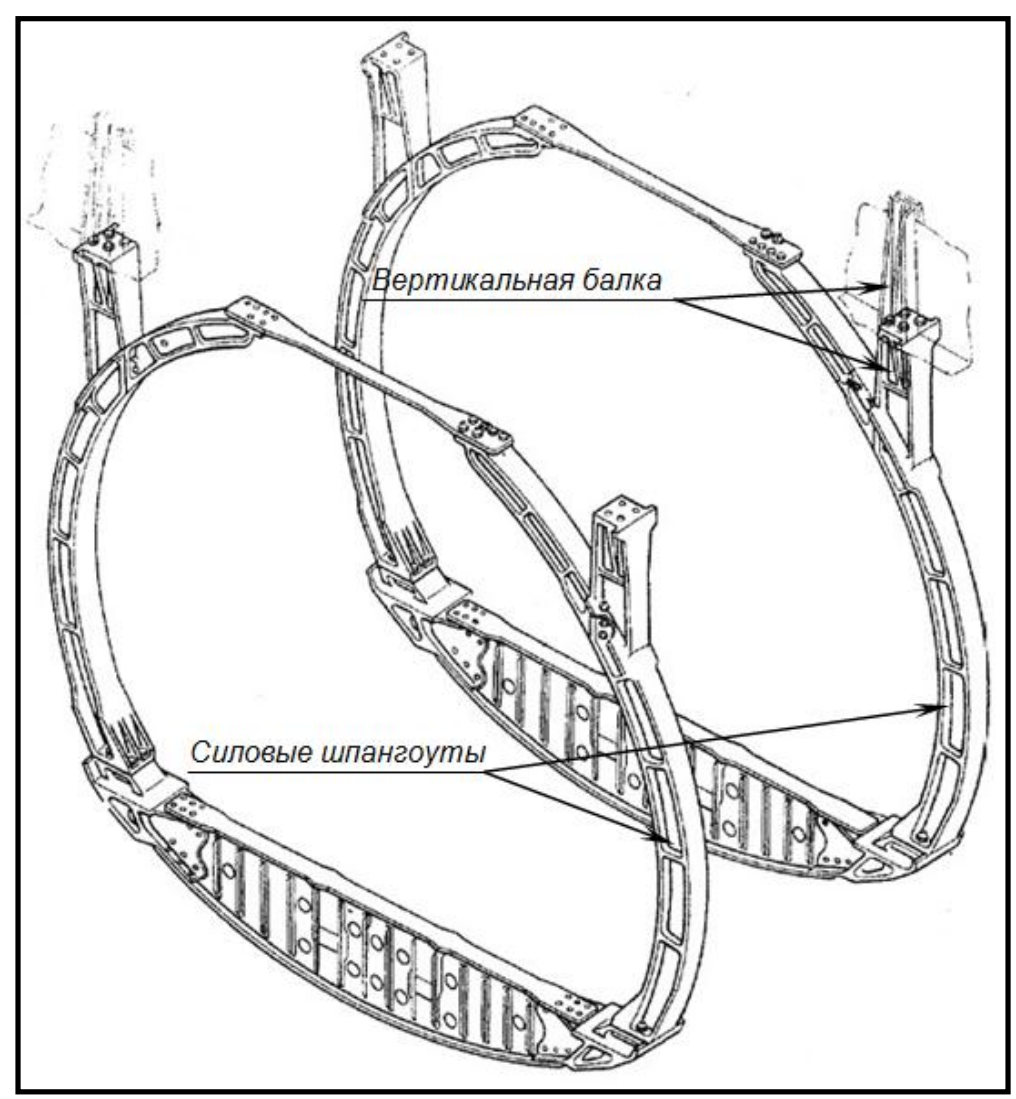

Рис. 3. Усиленные шпангоуты

Кроме того, практически невозможно определить зоны концентрации напряжений. В результате становится невозможным обеспечить усталостную прочность конструкции при минимальном весе силовых элементов. Для решения этой проблемы в результаты интегральных расчетов вводятся различные поправки, величина которых, в основном, определяется на основании эмпирических зависимостей, разработанных на основе экспериментальных данных, полученных для существующих классов конструкций. Однако, необходимость использования эмпирических поправок сужает диапазон конструкций, для которых может выполняться анализ напряженно-деформированного состояния (НДС).

Наиболее эффективным методом решения задачи определения влияния деформаций на распределение напряжений в конструкции является метод конечного элемента (МКЭ), который является универсальным методом расчета напряженно-деформированного состояния (НДС) произвольных конструкций.

В статье описываются методы синтеза конечно-элементных моделей элементов конструкции планера, соединяющих центроплан с центральным отсеком фюзеляжа грузового самолета транспортной категории, имеющего высоко расположенное крыло.

Методы разработаны на основе функционального принципа декомпозиции, описанного в [4], который позволяют автоматически синтезиро- 
вать конечно-элементные модели (КЭМ) соединительных элементов на основе данных об узлах, получаемых непосредственно из соединяемых моделей центроплана и центрального отсека фюзеляжа. Синтезируемые КЭМ являются частью общей КЭМ кессона крыла.

Показано, что предложенные методы позволяют существенно уменьшить объем исходных данных, необходимых для синтеза КЭМ соединительных элементов, ограничивая его только ссылками на соединяемые агрегаты планера.

При разработке методов синтеза учитывалось, что, в отличие от КЭМ фланцевого стыка центроплана и ОЧК, описанной в [5], синтезируемые модели должны обеспечивать предварительный анализ НДС моделируемых элементов конструкции. Данные о перемещениях узлов, получаемые в процессе расчета, также используются при задании нагрузок и граничных условий, необходимых для расчета НДС 3D-моделей, выполняемого с целью выявления зон концентрации напряжений.

\section{Анализ проблемы}

Взаимодействие фрагментов КЭМ в рамках общей модели возможно только тогда, когда в их структурах имеются конечные элементы (КЭ) с одинаковыми номерами узлов. Для объединения фрагментов КЭМ используются два метода, описанные в [4].

Поскольку КЭМ стыковых элементов соединяют предварительно сформированные модели центроплана и центрального отсека фюзеляжа, для их синтеза используется метод объединения, независимо сгенерированных КЭМ, в соответствии с которым фрагменты КЭМ объединяются с помощью дополнительных конечно-элементных структур, моделирующих стыковые элементы. Для его реализации необходимо обеспечить непосредственный обмен данными между синтезируемыми КЭМ стыковых элементов и готовыми КЭМ центроплана и отсека фюзеляжа, которые они объединяют. Поэтому используемая информационная технология (ИТ) должна обеспечивать управление доступом к моделям, позволяющее блокировать функции ручной корректировки объединяемых КЭМ перед началом процесса объединения. Однако, в отличие от метода синтеза КЭМ фланцевого стыка, описанного в статье [5], для присоединения КЭМ вертикальных балок и соединительных дуг к КЭМ кессона крыла требуется корректировка КЭМ центроплана, которая включает в себя следующие операции (рис. 4):

- изменение координат узлов в моделях нервюр центроплана в зоне расположения поясов, передающих продольные нагрузки;

- включение дополнительных сечений в структуру КЭМ центроплана для присоединения КЭМ вертикальных балок; 
Механіка елементів конструкиій

- перемещение нервюр, с учетом фактического положения смежных КЭМ.

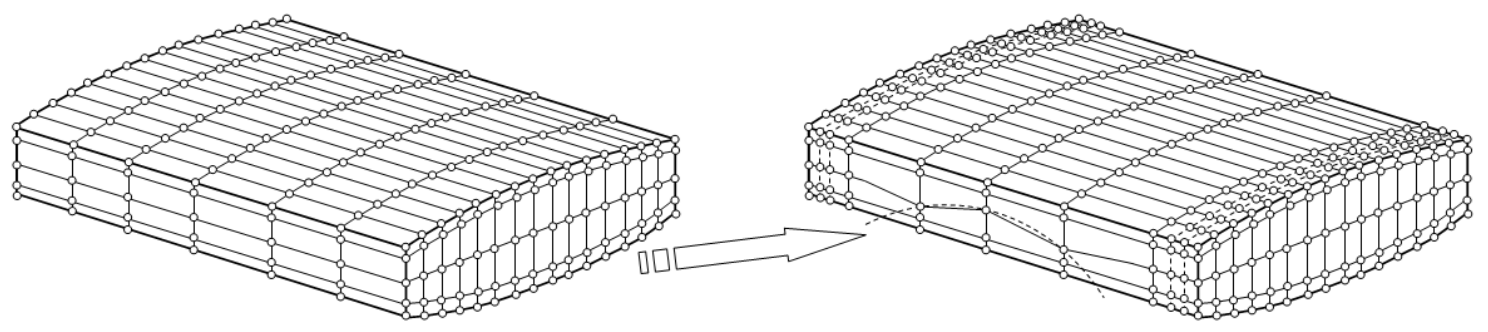

Рис. 4. Корректировка КЭМ центроплана

Таким образом, в отличие от КЭМ ОЧК, алгоритм синтеза КЭМ центроплана должен предусматривать возможность автоматической реструктуризации модели в процессе присоединения к модели фюзеляжа.

\section{Анализ нерешенных вопросов}

Алгоритм синтеза КЭМ планера транспортного самолета в зоне стыка кессона крыла с центральным отсеком фюзеляжа предусматривает автоматический обмен данными между КЭМ соединительных элементов и КЭМ соединяемых отсеков. При этом, объединение моделей соединительных элементов с моделями кессона крыла возможно только после реструктуризации КЭМ центроплана, которая должна выполняться автоматически. Поэтому реализация алгоритма синтеза КЭМ планера в зоне стыка центроплана с фюзеляжем возможна только с помощью ИТ, обеспечивающей решение следующих задач:

- формирование и поддержка активных КЭМ, обеспечивающих автоматический взаимный обмен данными;

- подключение специализированного алгоритма реструктуризации КЭМ центроплана.

Анализ ИТ, результаты которого приведены в [4], показал, что современные $C A E$-системы не позволяют формировать активные КЭМ, способные обмениваться данными без участия $C A E$-систем. Использование узкоспециализированных алгоритмов возможно только в рамках объектноориентированных систем управления данными, которые не входят в состав современных $C A E$-систем.

\section{Постановка задачи}

Целью данного исследования является разработка методов автоматизированного синтеза КЭМ вертикальных балок и продольных стенок зоны стыка кессона крыла с фюзеляжем. Согласно результатам исследований, 
приведенным в [4], наиболее оптимально задачи синтеза КЭМ планера транспортного самолета решаются с помощью объектной системы управления данными (ОСУБД) "SPACE", описанной в [6]. Поэтому методы синтеза должны разрабатываться с учетом особенностей объектноориентированной ИТ, реализованной в ОСУБД "SPACE". При этом структуры КЭМ стыковых элементов должны обеспечивать предварительный анализ их НДС.

\section{Декомпозиция КЭМ и схема обмена данными}

Для решения задачи разработки методов моделирования конструкций силовых элементов зоны стыка используется функциональный принцип декомпозиции КЭМ, описанный в [4]. КЭМ силовых элементов зоны стыка центроплана и фюзеляжа объединяют предварительно сформированные КЭМ указанных отсеков планера. Поэтому они находятся на верхнем уровне декомпозиции, вместе с КЭМ объединяемых отсеков. Модели нервюр, в соответствии с методами формирования КЭМ регулярных зон конструкции, описанными в [4], располагаются на нижнем, более детальном, уровне декомпозиции (рис. 5). Все модели, участвующие в процессе формировании КЭМ зоны стыка реализованы в виде объектов "SPACE".

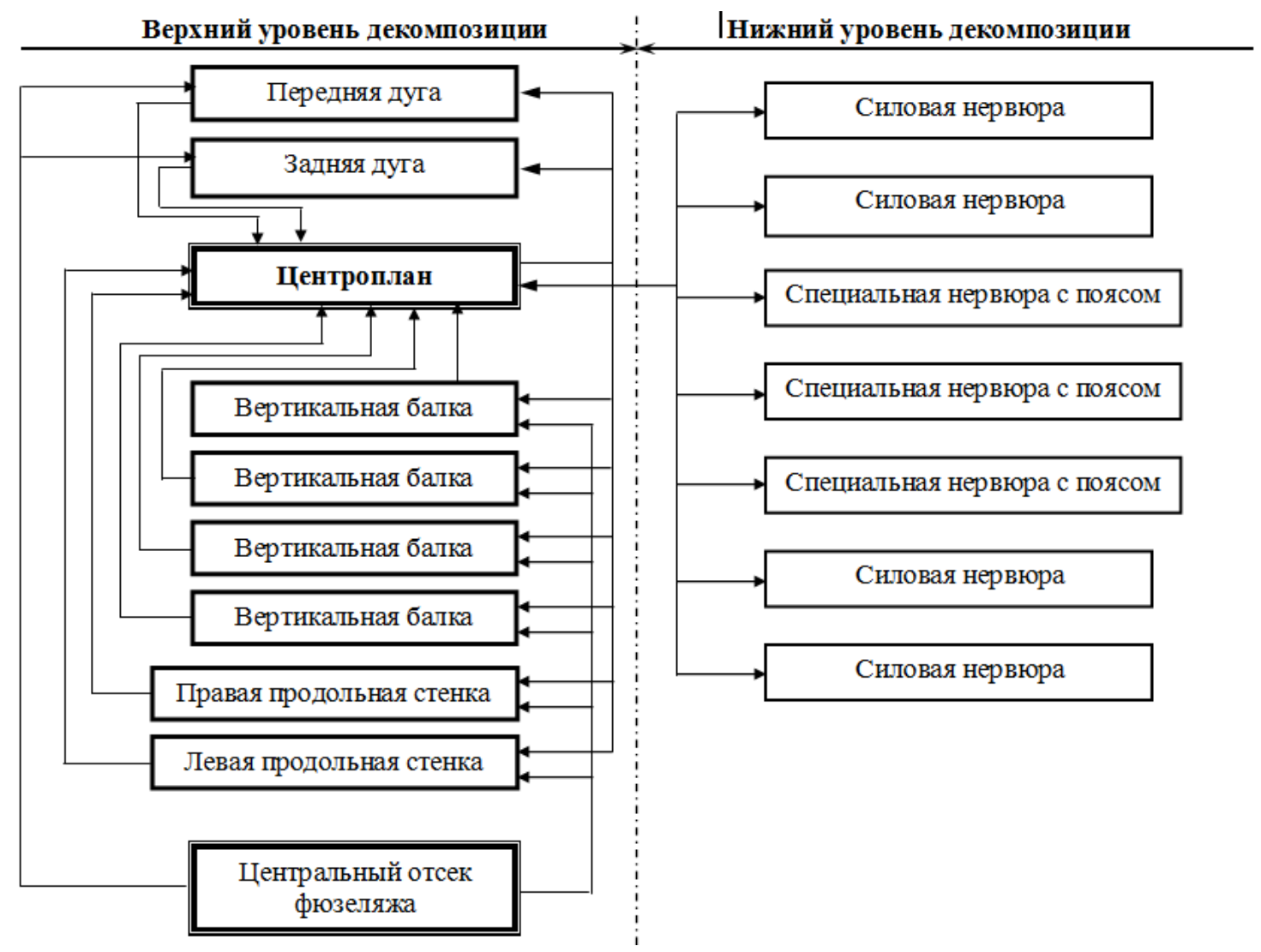

Рис. 5. Уровни декомпозиции и схема обмена данными при формировании КЭМ зоны стыка центроплана и фюзеляжа 
Перечни исходных данных, необходимых для формирования КЭМ описываемых стыковых элементов, зависят от алгоритмов моделирования, которые определяются их функциональным назначением. Часть данных вводится вручную с помощью пользовательского интерфейса, поддерживаемого соответствующими объектами. Данные об узлах контактных зон объединяемых КЭМ передаются через виртуальные структуры данных, в процессе прямого обмена данными между ними.

Для формирования КЭМ вертикальной балки, которая передает вертикальное усилие с крыла на силовой шпангоут фюзеляжа, требуются следующие исходные данные:

- ссылки на КЭМ нервюр и сечений отсека кессона крыла, с которыми контактирует КЭМ балки;

- ссылка на КЭМ шпангоута отсека фюзеляжа, к которой присоединяется КЭМ балки;

- номера узлов КЭМ нервюр и сечений отсека кессона крыла, расположенных в плоскости лонжерона, ближайшего к плоскости выбранного шпангоута;

- номера узлов внешнего контура КЭМ шпангоута, к которой присоединяется КЭМ балки.

Ссылки на нервюры, сечения и шпангоут задаются вручную, с помощью специального GUI, который поддерживается программными процедурами, входящими в состав объекта, предназначенного для синтеза КЭМ вертикальной балки (рис. 6). В процессе генерации объекта, в него передаются ссылки на КЭМ отсеков планера, входящие в состав общей КЭМ.

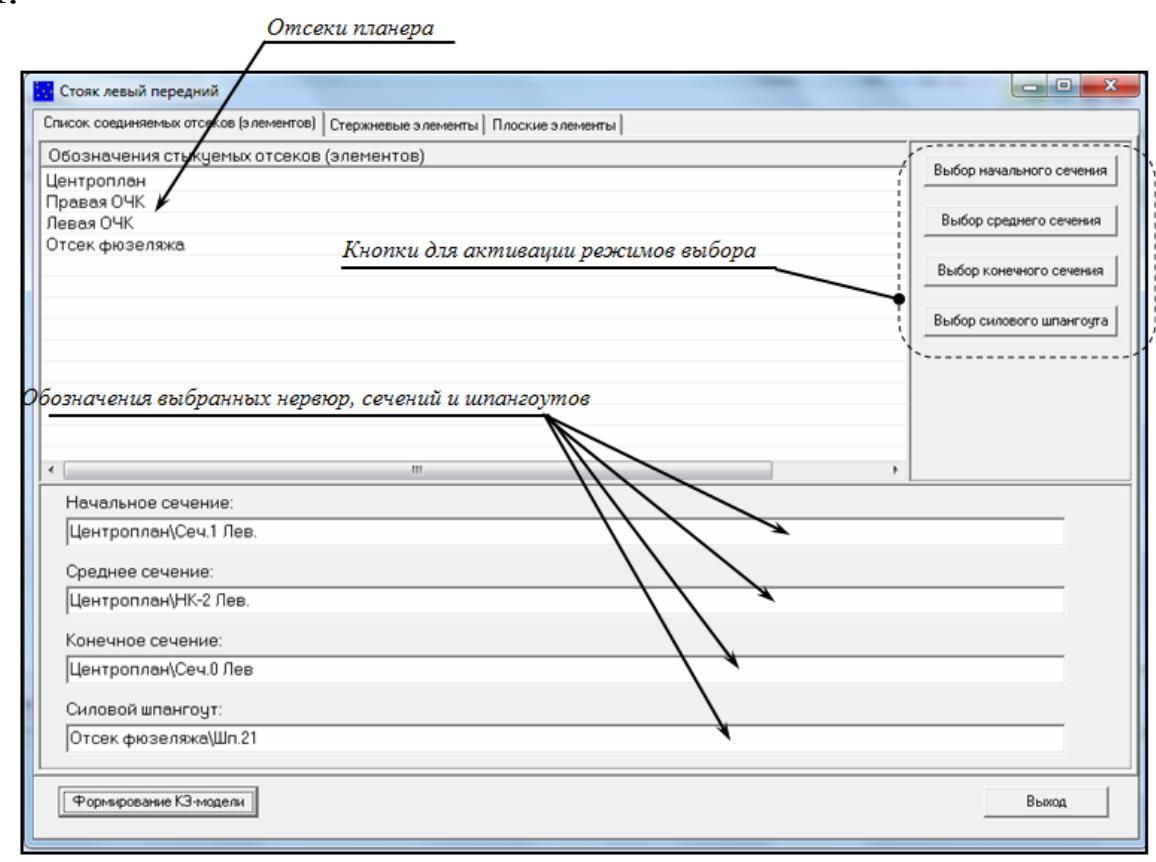

Рис. 6. GUI для задания ссылок на КЭМ нервюр, сечений и шпангоутов, соединенных с КЭМ балки 
Ссылки на соединяемые КЭМ отсеков планера передаются в виде индивидуальных кодов соответствующих объектов и номеров БД, в которых они хранятся. Номера узлов КЭМ нервюр и сечений передаются из объекта, содержащего КЭМ центроплана, через виртуальную структуру данных (рис. 7).

Номера узлов КЭМ усиленного шпангоута, к которой присоединяется КЭМ вертикальной балки, передаются через виртуальную структуру данных аналогичного формата из объекта, содержащего модель шпангоута (рис. 5).

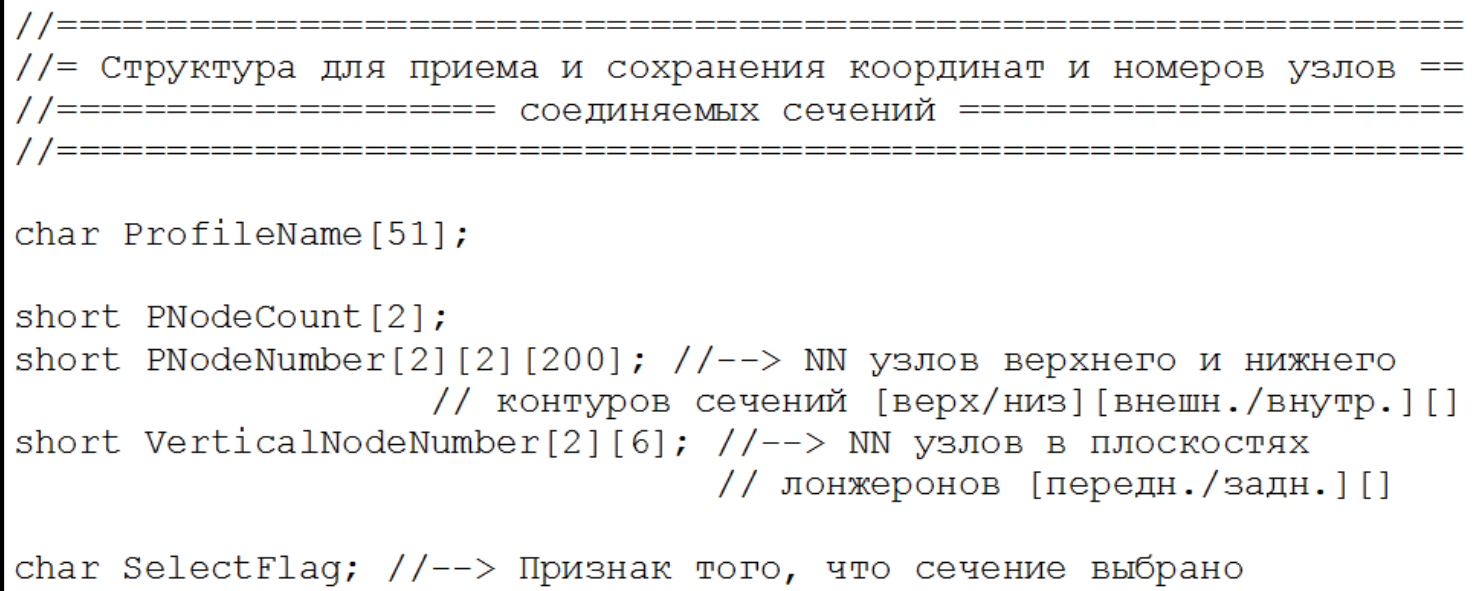

Рис. 7. Формат структуры для обмена данными с центропланом

Для формирования КЭМ стенки, передающей тягу двигателей и сопротивление крыла на продольные несущие элементы фюзеляжа, требуются следующие исходные данные:

- ссылки на КЭМ нервюры отсека кессона крыла, с которой передается продольная нагрузка;

- ссылка на КЭМ отсека фюзеляжа, к которому присоединяется КЭМ продольной стенки;

- номера узлов КЭМ, расположенных на нижнем контуре нервюры, с которой передаются нагрузки;

- номера узлов внешних контуров КЭМ шпангоутов, к которыми контактирует продольная стенка.

Ссылки на нервюру и отсек фюзеляжа задаются вручную, с помощью специального GUI, который поддерживается программными процедурами, входящими в состав объекта, предназначенного для синтеза КЭМ горизонтальной стенки (рис. 8). В процессе генерации объекта, в него передаются ссылки на КЭМ отсеков планера, входящие в состав общей КЭМ.

Номера узлов КЭМ нервюры передаются из объекта, содержащего КЭМ центроплана, через виртуальную структуру данных, формат которой приведен на рис. 7. 


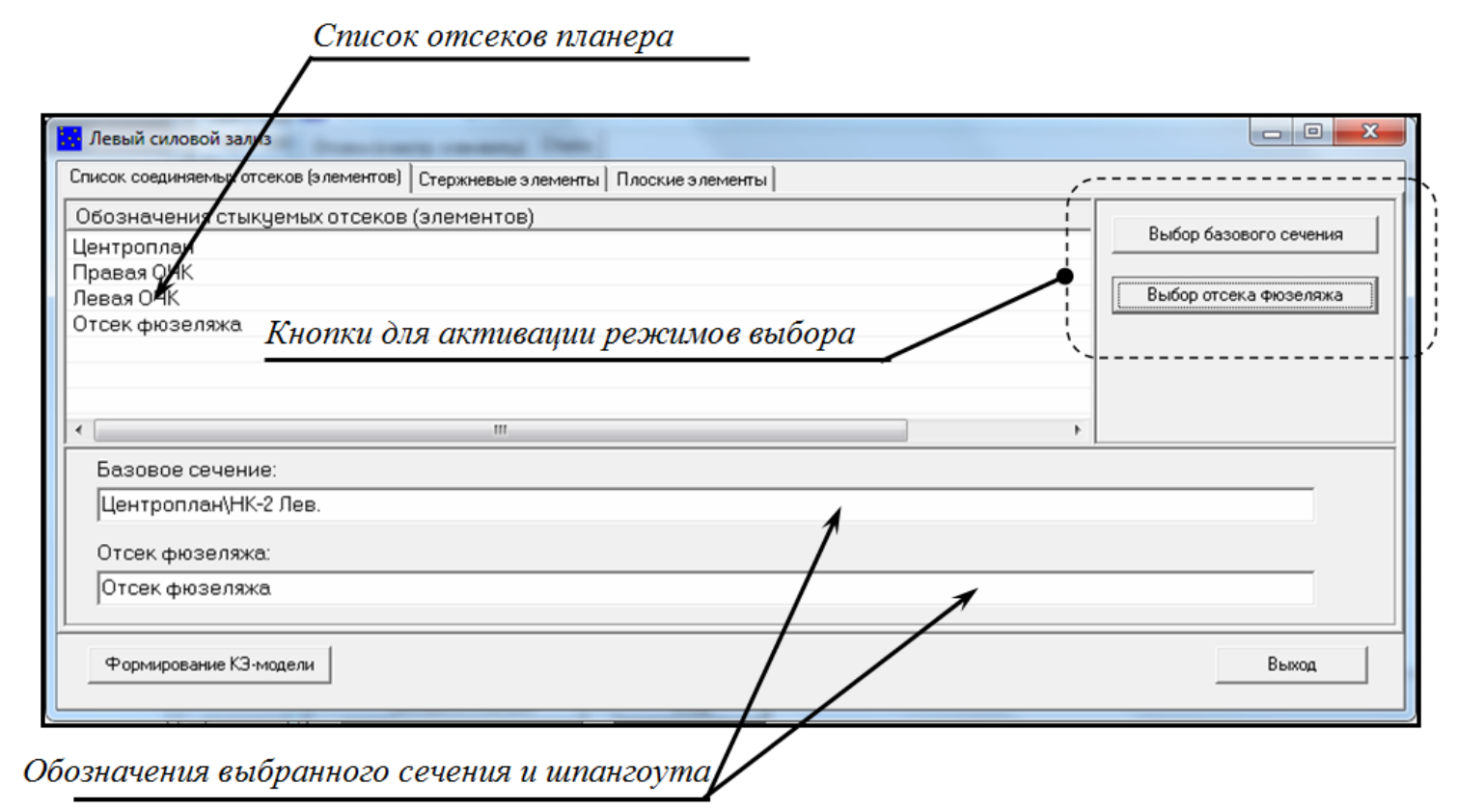

Рис. 8. GUI для задания ссылок на КЭМ нервюры и отсека фюзеляжа, соединенных с КЭМ продольной стенки

Номера узлов КЭМ шпангоутов, с которыми контактирует продольная стенка, передаются через виртуальную структуру данных, формат которой приведен на рис. 9.

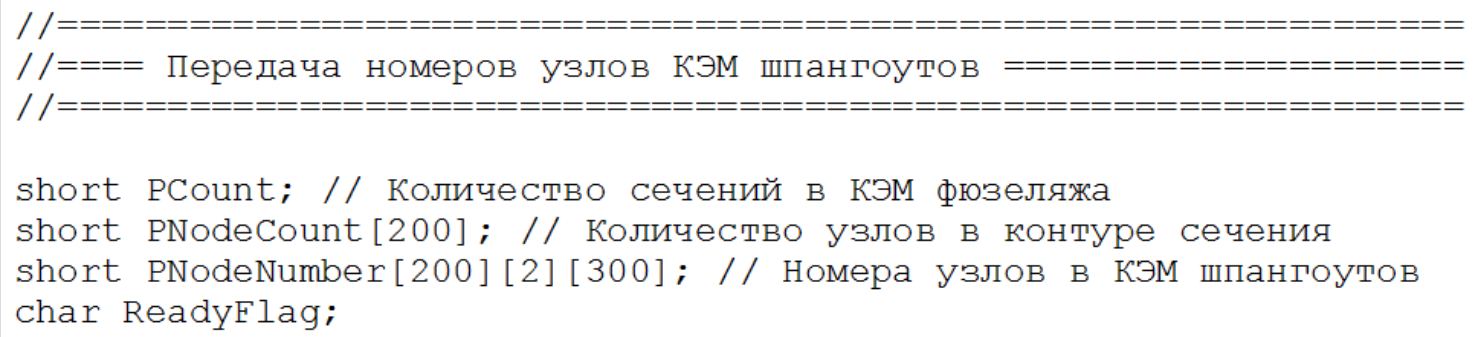

Рис. 9. Формат структуры для обмена данными с фюзеляжем

\section{Структура КЭМ в зоне стыка центроплана с фюзеляжем}

Структура КЭМ планера самолета, построенная в соответствии с предлагаемыми методами синтеза КЭМ вертикальных балок и продольных стенок, показана на рис. 10.

Модель не содержит КЭМ соединительных дуг, так как в данной статье не описывается метод их синтеза. Соответственно, КЭМ центроплана не содержит модели нервюр с продольными поясами, воспринимающими усилия от продольного набора фюзеляжа. Также представленная модель не содержит КЭМ усиленных шпангоутов, поскольку метод их синтеза также не описан в данной статье. 
Механіка гіроскопічних систем

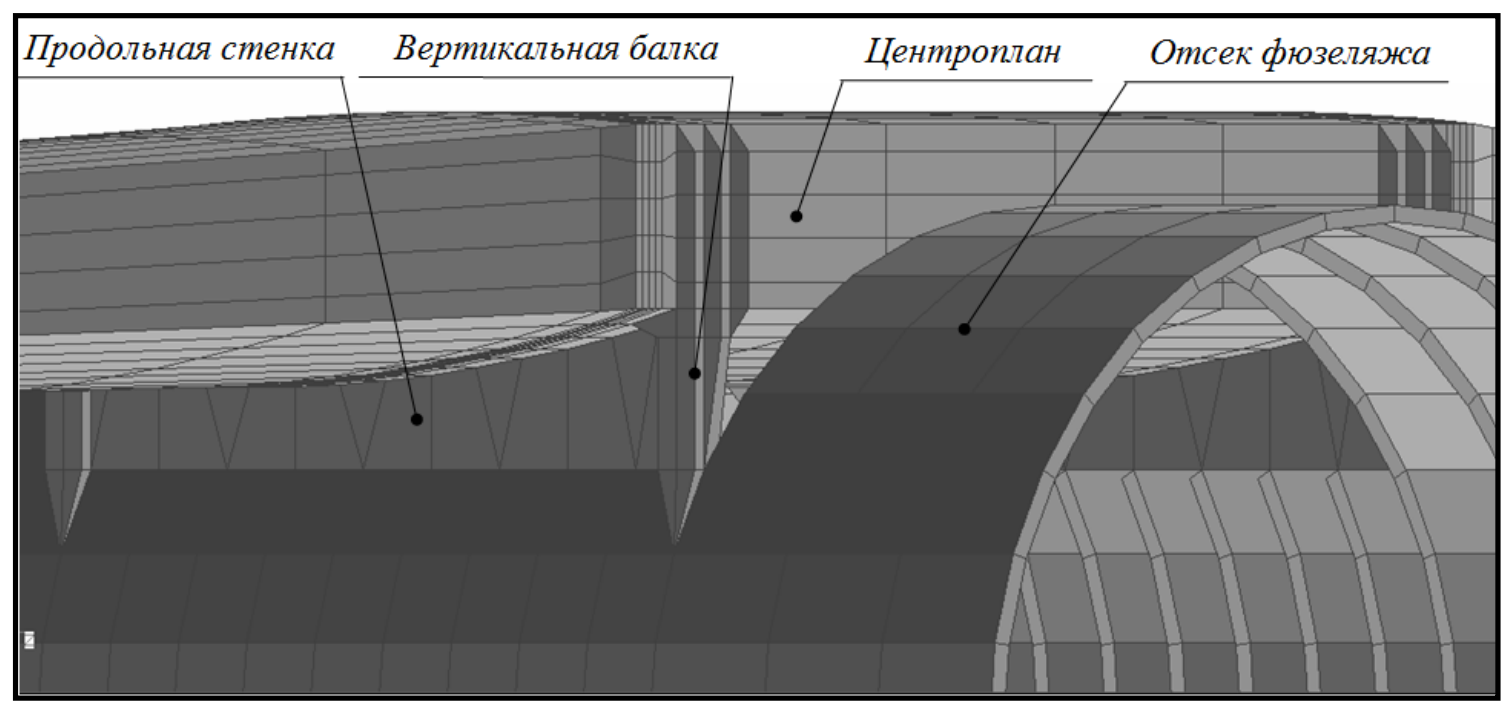

Рис. 10. Структура КЭМ в зоне стыка центроплана с фюзеляжем

Для большей наглядности, в моделях кессона крыла и фюзеляжа уменьшено количество КЭМ нервюр и стрингеров.

Предлагаемые методы автоматизированного синтеза разработаны с учетом внутреннего представления КЭМ, описанного в [4]. При этом модели вертикальных балок содержат не только граничные узлы, уже имеющиеся в КЭМ соединяемых отсеков, но также и собственные узлы, которые добавляются к уже существующему массиву узлов общей КЭМ. В результате существенно усложняется алгоритм задания номеров узлов в копиях КЭМ вертикальных балок и продольных стенок, которые передаются в объект, формирующий общую КЭМ.

\section{Метод синтеза КЭМ вертикальной балки}

Метод синтеза КЭМ вертикальной балки включает в себя три этапа.

На первом этапе выполняется чтение номеров граничных узлов КЭМ нервюр и сечений центроплана, с которыми контактирует КЭМ вертикальной балки. Чтение номеров осуществляется автоматически, непосредственно в процессе выбора нервюр и сечений, и выполняется в следующей последовательности:

Шаг 1. Выбор отсека кессона и активизация режима выбора нервюры или сечения, с которыми будет контактировать вертикальная балка. Выбор отсека и активизация режима выбора нервюры или сечения осуществляются в ручном режиме, с помощью GUI, изображенного на рис. 5.

Шаг 2. Выбор нервюры или сечения, с которыми будет контактировать вертикальная балка. Выбор нервюры или сечения осуществляются в ручном режиме, с помощью GUI, изображенного на рис. 11, кото- 
рый появляется на экране в результате активизации объекта, содержащего КЭМ центроплана.

Шаг 3. Передача номеров узлов КЭМ выбранной нервюры или сечения из объекта, содержащего КЭМ иентроплана, в объект, содержащуий КЭМ вертикальной балки. Передача номеров узлов выполняется через виртуальную структуру данных, формат которой показан на рис. 6. Инициализация виртуальной структуры осуществляется каждый раз, когда объект, содержащий КЭМ центроплана, активизируется в режиме выбора нервюры или сечения.

Окно для выбора нервюры

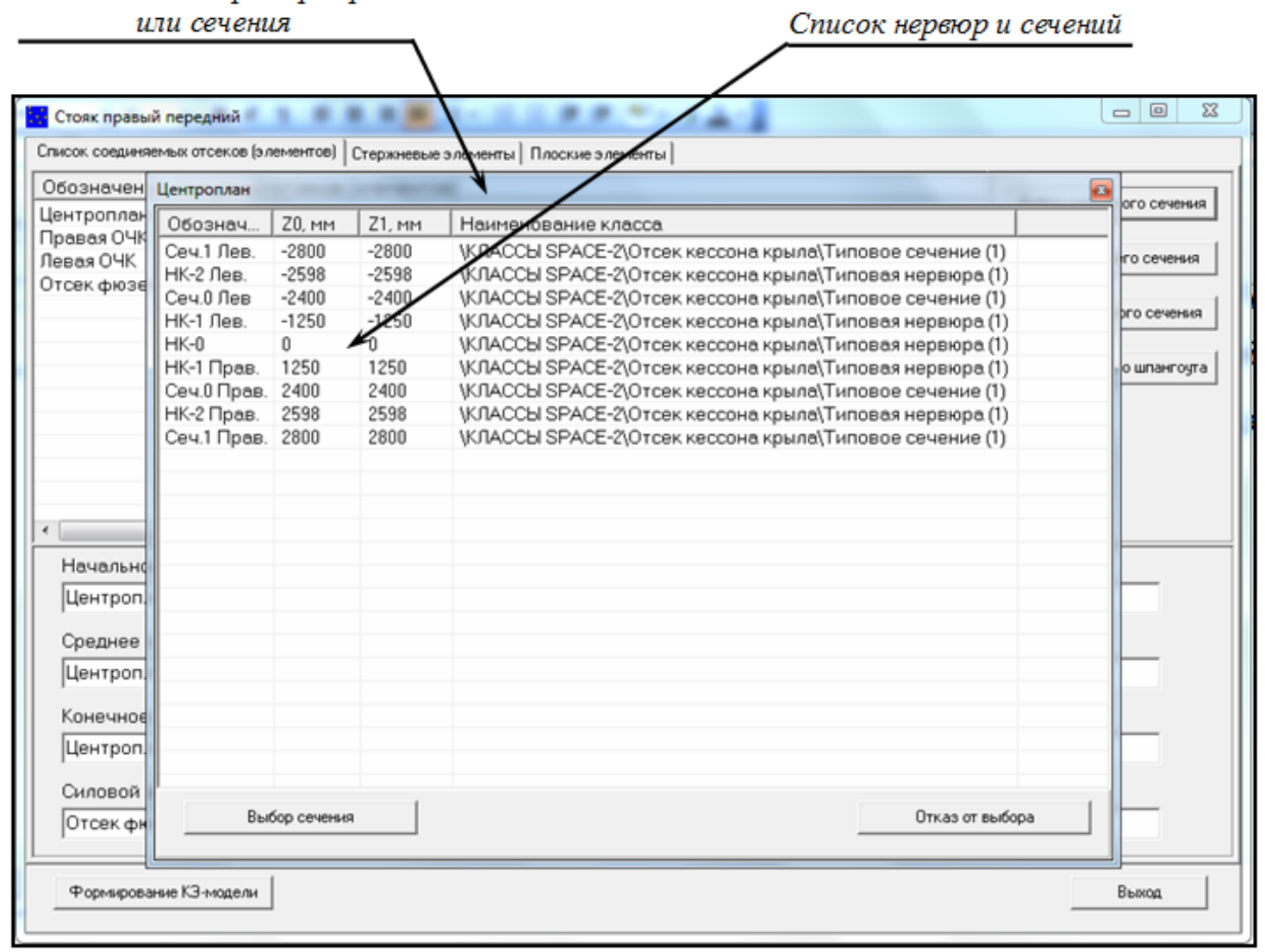

Рис. 11. Выбор нервюры или сечения центроплана

Шаг 4. Переход. Если выбраны все три нервюры (сечения центроплана), то переход на Шаг 5. Иначе возврат к Шагу 1.

Шаг 5. Выбор отсека фюзеляжа и активизация режима выбора шпангоута, с которым будет контактировать вертикальная балка. Выбор отсека фюзеляжа и активизация режима выбора шпангоута также осуществляются в ручном режиме, с помощью GUI, изображенного на рис. 5.

Шаг 6. Выбор шпангоута, с которым будет контактировать вертикальная балка. Выбор шпангоута осуществляются в ручном режиме, с помощью GUI, изображенного изображенному на рис. 11, который 
появляется на экране в результате активизации объекта, содержащего КЭМ отсека фюзеляжа.

Шаг 7. Передача номеров узлов КЭМ выбранного шпангоута из объекта, содержащего КЭМ отсека фюзеляжа, в объект, содержащчий КЭМ вертикальной балки. Передача номеров узлов выполняется через виртуальную структуру данных, формат которой показан на рис. 6. Инициализация виртуальной структуры осуществляется каждый раз, когда объект, содержащий КЭМ отсека фюзеляжа, активизируется в режиме выбора нервюры или сечения.

Шаг 8. Определение лонжерона, с которым контактирует вертикальная балка. Лонжерон, с которым контактирует вертикальная балка, определяется с учетом координаты Х выбранного шпангоута.

Шаг 9. Чтение номеров узлов КЭМ нервюр (сечений). Чтение номеров узлов КЭМ нервюр (сечений) осуществляется из массивов номеров узлов, расположенных в плоскости лонжерона, с которым контактирует вертикальная балка. Указанные массивы заполняются при передаче номеров узлов из объекта, содержащего КЭМ центроплана.

Шаг 10. Чтение номеров узлов КЭМ шпангоута. Читаются номера трех узлов внешнего контура КЭМ шпангоута, которые расположены наиболее близко к плоскостям нервюр (сечений) центроплана, с которыми контактирует вертикальная балка. Указанные массивы заполняются при передаче номеров узлов из объекта, содержащего КЭМ фюзеляжа.

Шаг 11. Окончание.

На втором этапе осуществляется расчет координат собственных узлов КЭМ вертикальной балки, который выполняется в следующей последовательности.

Шаг 1. Определение координат контактных узлов соединяемых отсеков планера. Координаты контактных узлов соединяемых отсеков планера определяются на основании их номеров, которые передаются в объект на первом этапе процесса синтеза КЭМ балки, путем считывания из общего массива координат узлов, который автоматически передается из объекта, содержащего общую КЭМ.

Шаг 2. Определение координат внешних и внутренних узлов моделей ребер жесткости. Количество внешних узлов в модели ребра жесткости определяется количеством узлов в сечении модели лонжерона, чья структура подробно описывается в [4]. Координаты внешних узлов отличаются от координат узлов, расположенных в плоскости лонжерона на постоянную величину $\Delta X$, которая определяется высотой сечения лонжерона. Для переднего лонжерона $\Delta X<0$, для заднего $\Delta X>0$. В качестве внутренних узлов используются узлы бли- 
жайшего сечения нервюры, чья плоскость совпадает с плоскостью ребра (рис. 12):

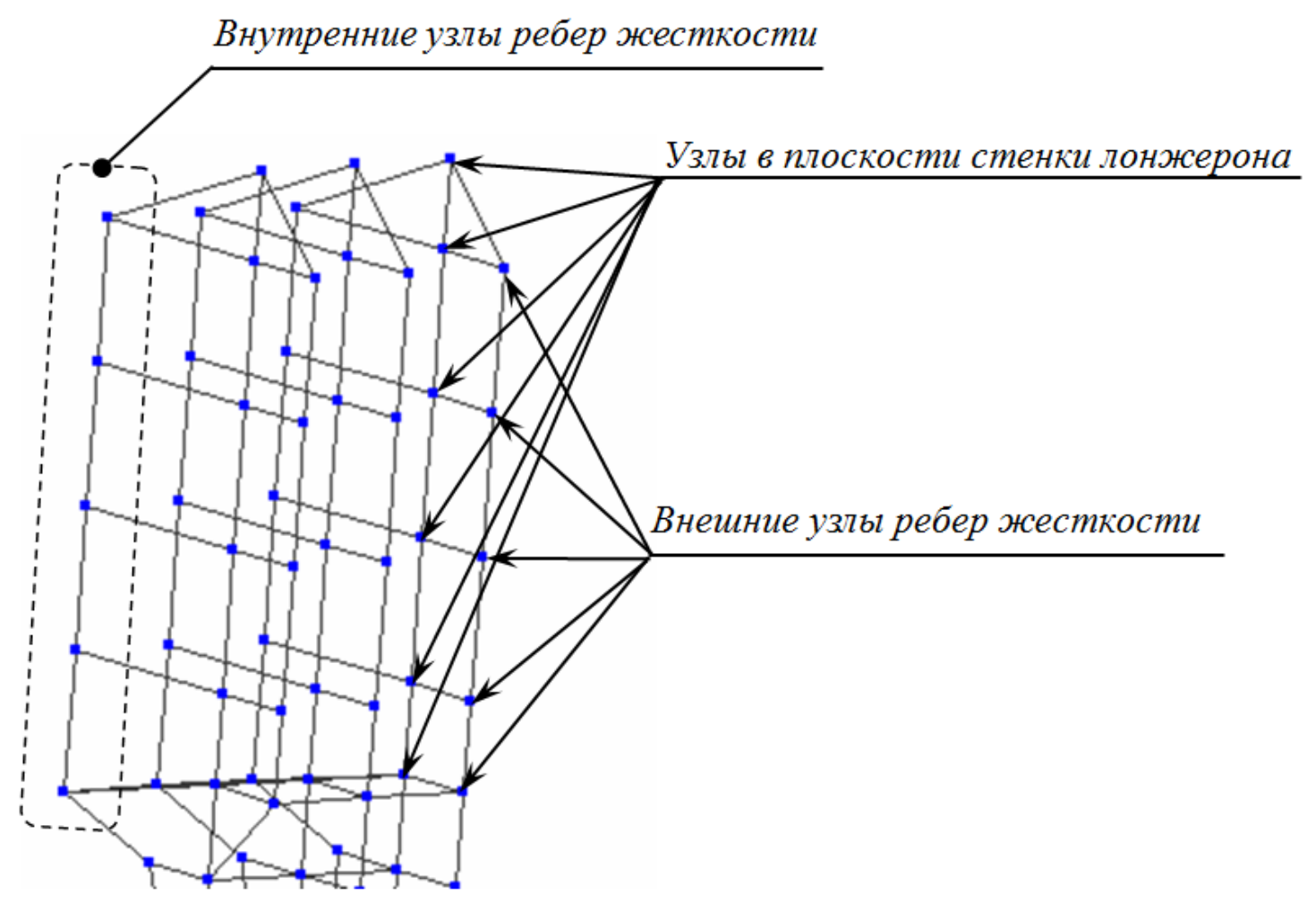

Рис. 12. Узлы КЭМ ребер усиления

Шаг 3. Определение координат узлов моделей опорных стоек. Узлы модели опорной стойки, соединяющей модель лонжерона с моделью усиленного шпангоута, делятся на две группы: узлы, расположенные в плоскости стойки, и внешние узлы ребер жесткости. Узлы, расположенные в плоскости стойки, также делятся на две группы. Первая группа включает в себя три узла, чьи координаты отличаются от координат нижних узлов сечений лонжерона на постоянную величину $\Delta Y<0$. Значение $\Delta Y$ зависит от ширины стойки. Вторая группа включает один узел, чьи координаты отличаются от координат внешнего контактного узла модели шпангоута на величину $\Delta Y$. Для правой вертикальной балки $\Delta Y>0$, для левой балки $\Delta Y<0$. Принцип определения координат узлов моделей ребер жесткости стойки аналогичен принципу определения координат узлов моделей ребер жесткости, описанному для Шага 2.

Шаг 4. Окончание.

На третьем этапе производится описание конечных элементов. КЭМ вертикальной балки включает в себя только плоские КЭ, которые могут воспринимать все виды нагрузок, например, элементы типа "Plate" в MSC Nastran. Общий вид КЭМ вертикальной балки показан на рис. 13. 


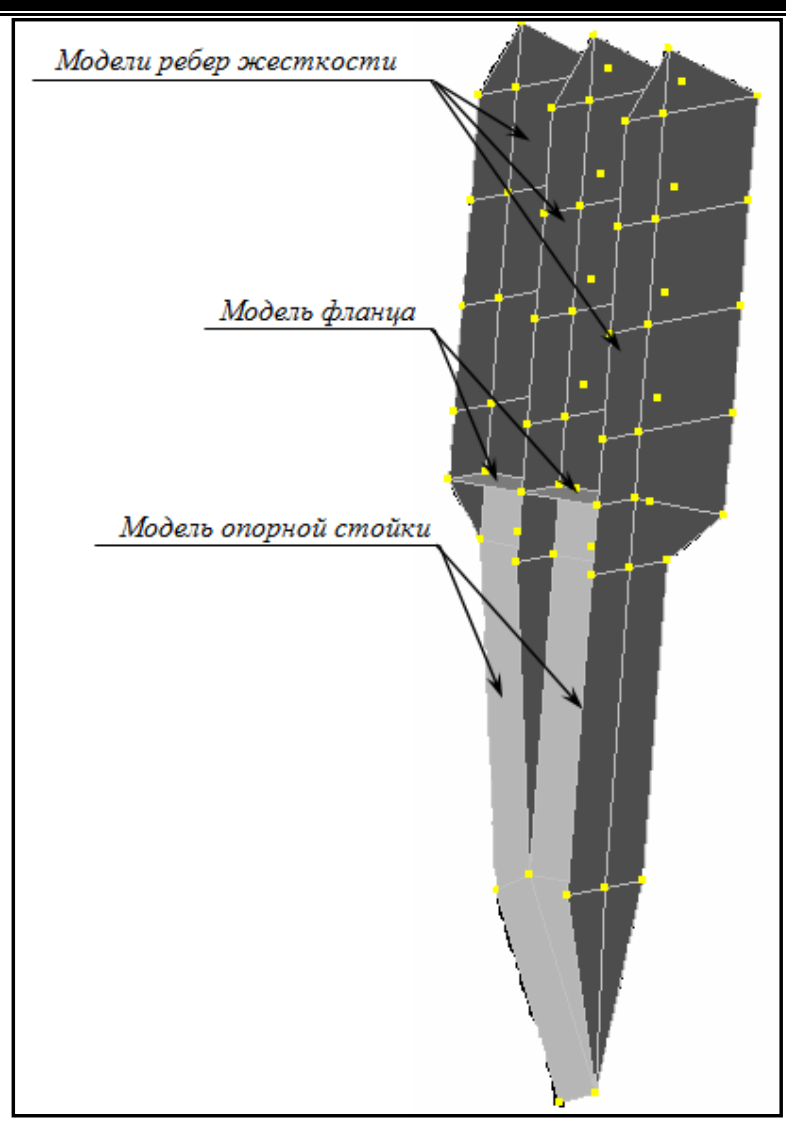

Рис. 13. КЭМ вертикальной балки

Шаг 1. Описание зоны фланцевого соединения. Структура КЭМ в зоне фланцевого соединения состоит из четырехугольных КЭ, которые опираются на нижние узлы моделей ребер жесткости.

Шаг 2. Описание моделей ребер жесткости в зоне лонжерона. Структура КЭМ ребер жесткости в зоне лонжерона состоит из четырехугольныХ и треугольных КЭ, которые опираются на внешние и внутренние узлы, указанные в описании предыдущего этапа, а также на узлы, расположенные в плоскости лонжерона. Треугольные КЭ расположены в верхней части моделей ребер (рис. 13).

Шаг 3. Описание модели опорной стойки. Структура КЭМ опорной стойки, соединяющей лонжерон с усиленным шпангоутом, опирается на контактные узлы, расположенные в плоскости лонжерона и на внешнем контуре модели усиленного шпангоута, а также на дополнительные узлы, указанные в описании предыдущего этапа.

Шаг 4. Моделирование ребер жесткости опорной стойки. Структура КЭМ ребер жесткости опорной стойки, соединяющей лонжерон с усиленным шпангоутом, включает в себя четырехугольные и треугольные КЭ. Треугольные КЭ расположены в нижней части моделей ребер, в зонах контакта с КЭМ шпангоута.

Шаг 5. Окончание. 


\section{Метод синтеза КЭМ продольной стенки}

Метод синтеза КЭМ продольной стенки также включает в себя два этапа, поскольку модель стенки содержит только контактные узлы, которые входят в структуры КЭМ центроплана и отсека фюзеляжа.

На первом этапе осуществляется выбор нервюры и отсека фюзеляжа, с которыми контактирует КЭМ продольной стенки, а также чтение номеров граничных узлов КЭМ нервюры. Чтение осуществляется автоматически, непосредственно в процессе выбора нервюры. На этом этапе выполняются следующие действия:

Шаг 1. Выбор отсека кессона и активизаиия режима выбора нервюры, с которой будет контактировать горизонтальная стенка. Выбор отсека и активизация режима выбора нервюры осуществляются в ручном режиме, с помощью GUI, изображенного на рис.7.

Шаг 2. Выбор нервюры, с которой будет контактировать продольная стенка. Выбор нервюры осуществляются в ручном режиме, с помощью GUI, изображенного на рис. 11, который появляется на экране в результате активизации объекта, содержащего КЭМ центроплана.

Шаг 3. Передача номеров узлов КЭМ выбранной нервюры из объекта, содержащего КЭМ иентроплана, в объект, содержащий КЭМ продольной стенки. Передача номеров узлов выполняется через виртуальную структуру данных, формат которой показан на рис. 6. Инициализация виртуальной структуры осуществляется каждый раз, когда объект, содержащий КЭМ центроплана, активизируется в режиме выбора нервюры.

Шаг 4. Выбор отсека фюзеляжа, с которым будет контактировать продольная стенка и фиксация ссылки на объект, содержащий КЭМ отсека. Выбор отсека фюзеляжа также осуществляются в ручном режиме, с помощью GUI, изображенного на рис. 7.

Шаг 5. Окончание.

На втором этапе осуществляется чтение координат узлов КЭМ шпангоутов, с которыми контактирует КЭМ продольной стенки, а также синтез КЭМ продольной стенки. На этом этапе выполняются следующие действия:

Шаг 1. Определение номеров узлов КЭМ шпангоутов, с которыми контактирует КЭМ продольной стенки. Номера узлов КЭМ шпангоутов, с которыми контактирует КЭМ продольной стенки, передаются через виртуальную структуру данных, формат которой показан на рис. 8. Передача номеров узлов выполняется автоматически, при обращении объекта, содержащего КЭМ продольной стенки к объекту, содержащему КЭМ отсека фюзеляжа (рис. 4). 
Шаг 2. Определение координат контактных узлов соединяемых отсеков планера. Координаты контактных узлов соединяемых отсеков планера определяются на основании их номеров, которые передаются в объект на первом этапе процесса синтеза КЭМ продольной стенки, путем считывания из общего массива координат узлов, который автоматически передается из объекта, содержащего общую КЭМ.

Шаг 3. Описание КЭ. В отличие от модели вертикальной балки, КЭМ продольной стенки состоит из плоских и стержневых КЭ. Плоские КЭ воспринимают все виды нагрузок. Стержневые КЭ моделируют стойки и должны воспринимать изгиб и кручение. Количество контактных узлов, на нижнем контуре КЭМ нервюры центроплана больше количества КЭМ шпангоутов, с которыми контактирует КЭМ стенки. Поэтому КЭМ продольной стенки, кроме четырехугольных КЭ, включает треугольные КЭ. Общий вид КЭМ продольной стенки показан на рис. 14.

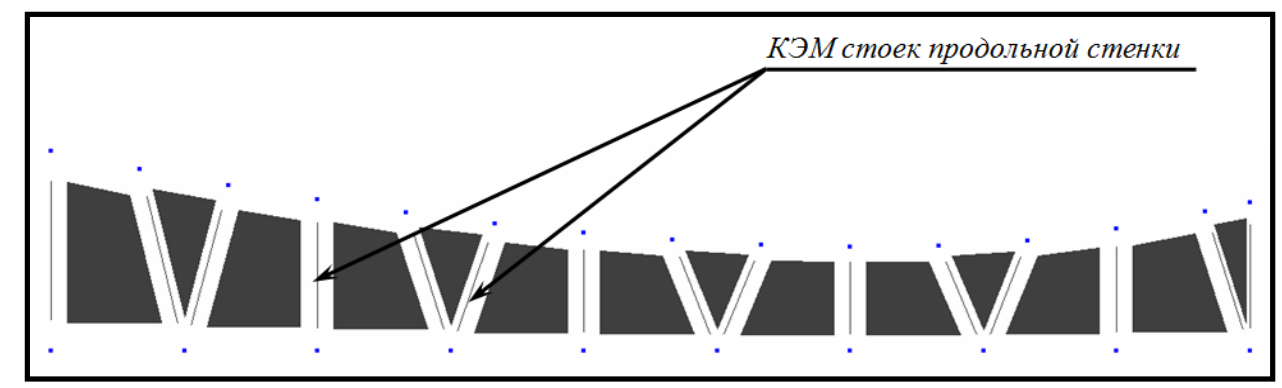

Рис. 14. КЭМ продольной стенки

\section{Реализация методов}

Особенностью предлагаемых методов автоматизированного синтеза КЭМ является прямой обмен данными с соединяемыми КЭМ (рис. 4), без участия пользователей САЕ-системы. Использование прямого обмена данными позволяет существенно сократить объем данных, вводимых "вручную". Например, суммарный объем массивов номеров и координат базовых узлов для КЭМ вертикальных балок и продольных стенок среднего самолета транспортной категории (22 стрингера на нижней поверхности центроплана и 6 шпангоутов в зоне контакта продольной стенки с фюзеляжем) составляет 420 значений. Количество элементов исходных данных, которые необходимо ввести, при использовании предлагаемых методов, равно 20 (ссылки на нервюры и сечения, ссылки на шпангоуты).

\section{Выводы}

На основании проведенного анализа можно сделать вывод, что разработанные методы позволяют повысить качество проектирования кессона крыла самолета транспортной категории, за счет увеличения количества исследуемых вариантов конструкции и уменьшить вероятность возникновения ошибок. 


\section{Список использованной литературы}

1. Одиноков Ю. Г. Расчет самолета на прочность / Ю. Г. Одиноков. Москва: Машиностроение, 1973. - 392 с.

2. Глаголев A. H. Конструкция самолетов / А. Н. Глаголев, М. Я. Гильдинов, С. М. Григоренко. - Москва: Машиностроение, 1975. $-480 \mathrm{c}$.

3. Егер С. М. Проектирование самолетов / С. М. Егер. - Москва: Машиностроение, 1983. - $616 \mathrm{c.}$

4. Борисов В. В. Методы синтеза конечно-элементной модели планера грузового самолета / В. В. Борисов. - Саарбрюккен: LAP LAMBERT Academic Publishing, 2014. - 139 c.

5. Борисов В. В. Метод автоматизированного синтеза конечноэлементной модели стыка центроплана и отъемной части кессона крыла самолета транспортной категории / В. В. Борисов, В. В. Сухов. // Известия вузов. Авиационная техника. - 2014. - №1. - С. 6-13.

6. Борисов В. В. Система автоматизированного управления проектными данными. / В. В. Борисов, В. П. Зинченко, И. П. Муха. // Адаптивные системы автоматизированного управления.. - 2011. - №19. - С. 23-34. 